\title{
Flow control effect of necrostatin-1 on cell death of the NRK-52E renal tubular epithelial cell line
}

\author{
JIALUN LUO ${ }^{1,2^{*}}$, YIMING TAO $^{1,2^{*}}$, XINLING LIANG ${ }^{1,2}$, YUANHAN CHEN $^{2}$, LI ZHANG $^{1,2}$, \\ FEN JIANG ${ }^{3}$, SHUANGXIN LIU ${ }^{2}$, ZHIMING YE ${ }^{2}$, ZHILIAN LI $^{2}$ and WEI SHI ${ }^{2}$ \\ ${ }^{1}$ Southern Medical University, Guangzhou, Guangdong 510515; ${ }^{2}$ Department of Nephrology, \\ Guangdong General Hospital, Guangdong Academy of Medical Sciences, Guangzhou, Guangdong 510080; \\ ${ }^{3}$ Department of Nephrology, The First Affiliated Hospital of Nanhua University, Hengyang, Hunan 421001, P.R. China
}

Received January 19, 2016; Accepted February 14, 2017

DOI: $10.3892 / \mathrm{mmr} .2017 .6556$

\begin{abstract}
Apoptosis and necroptosis occur in renal tubular epithelial cell (RTEC) death in acute kidney injury (AKI), and may be regulated by several methods. The present study identified a protective effect of necrostatin-1 (Nec-1) on RTECs via a flow-control-like effect. The results established a hypoxic-ischemic injury model of rat NRK-52E RTECs using tumour necrosis factor- $\alpha$ followed by ATP depletion with antimycin A and the pan-caspase pathway blocker, benzyloxycarbonyl-Val-Ala-Asp-fluoro-methylketone. Following pre-treatment of cells with Nec-1, cell organelle inflation, fragmentation inhibition and improved cell viability were observed with a parallel reduced expression of microtubule-associated protein 1A/1B-light chain 3-II. Nec-1 was involved in flow control in the process of cell injury and death. In conclusion, the present study indicated that $\mathrm{Nec}-1$ provides a protective effect and serves an important role in the prevention of AKI in an NRK-52E cell model. Further studies will be required to fully investigate the role of Nec-1 in the development of AKI in vivo.
\end{abstract}

\section{Introduction}

Acute kidney injury (AKI) is a common and serious complication characterized by a sharp decline in the glomerular filtration rate (GFR) $(1,2)$. AKI typically arises over a short period of time and significantly increases morbidity and mortality (1). In many cases, AKI results in poor short- and long-term prognoses (2). Renal tubular epithelial cell (RTEC)

Correspondence to: Dr Xinling Liang, Department of Nephrology, Guangdong General Hospital, Guangdong Academy of Medical Sciences, 106 Zhongshan Er Road, Guangzhou, Guangdong 510080, P.R. China

E-mail: dr_xlliang@126.com

*Contributed equally

Key words: acute kidney injury, necroptosis, flow control, renal tubular epithelial cells injury is the main cause and underlying mechanism of AKI induced by ischemia-hypoxia (3). The occurrence of cell death in RTEC injury may be regulated via several mechanisms.

Recently, in addition to the three mechanisms of cell death (apoptosis, autophagy and necrosis), a fourth mechanism of cell death has been described: Necroptosis (4). Necroptosis differs from apoptosis and autophagy in many ways (5). Necroptosis is a type of necrosis that is promoted by death receptor ligands when the apoptosis signalling pathway is inhibited. It is dependent on the activity of receptor-interacting protein kinase (RIP)1, and is a type of programmed cell death (6). Generally, when receiving a death signal, RIP1 activates caspase- 8 and initiates apoptosis. However, if the caspase- 8 signalling pathway is inhibited, RIP1 activates NADPH oxidase, thus producing reactive oxygen species and activating the necroptosis signalling pathway (7). Typically, apoptosis is a major cell death pathway. However, when this pathway is inhibited, for example following treatment with the caspase inhibitor benzyloxycarbonyl-Val-Ala-Asp-fluoro-methylketone (zVAD-fmk), necroptosis becomes dominant (8). RIP1 is a critical factor in the necroptosis signaling pathway and is regulated by a specific inhibitor, necrostatin-1 (Nec-1) $(9,10)$. Investigating these factors may provide insight into novel treatments for AKI.

In addition, the type of cell death may be more important than whether a cell dies. A necrotic cell may lead to the leakage of inflammatory substances and cause severe tissue damage, whereas an apoptotic cell does not. Thus, the type of cell death underlying AKI requires further study.

Our previous study indicated that during the AKI process induced by tumour necrosis factor (TNF)- $\alpha$, the NRK52-E RTEC line suffered injury that resulted in all types of cell death. Additionally, Nec-1 may additionally protect RTECs from ischemia injury-induced apoptosis via a dynamin-related protein (DRP1)-dependent mechanism (11). On the basis of these findings, additional factors were included for further investigation (11), such as the mitochondrial damage-related genes Drp-1, Cyclophilin D, c-Jun N-terminal kinase, and factors of ischemia and hypoxia in NRK52E cells.

TNF damage and ATP depletion are involved in ischemia injury (12). Therefore, the present study aimed to assess these mechanisms in AKI by inducing damage to NRK-52E cells using TNF- $\alpha$, followed by treatment with antimycin A 
to inhibit mitochondrial respiration to stimulate an ischemic and hypoxic environment (13). Following this, zVAD-fmk and Nec-1 were added to identify novel targets that may regulate the underlying mechanism and quantity of cell death.

\section{Materials and methods}

Materials. The NRK-52E cell line was obtained from the American Type Culture Collection (CRL-1571; ATCC; Manassas, VA, USA). A vertical electrophoresis unit (BIO-RAD 300; Bio-Rad Laboratories, Inc., Hercules, CA, USA), microplate reader (Multiskan MK3, Thermo Fisher Scientific, Inc., Waltham, MA, USA), image analyser (Q500IW; Leica Microsystems GmbH, Wetzlar, Germany), light microscope (Olympus Corporation, Tokyo, Japan), and hypothermia high-speed centrifuge (Beckman Coulter, Inc., Brea, CA, USA) were used in the present study.

Recombinant human TNF- $\alpha$ (cat. no. 96-300-01A-10; PeproTech, Inc., Rocky Hill, NJ, USA), zVAD-fmk, antimycin A (ALX-260-020-M005; Enzo Life Sciences, Inc., Farmingdale, NY, USA), Nec-1 (ALX-430-136; Enzo Life Sciences, Inc.) were used. The following primary antibodies were used for the study: microtubule-associated protein 1A/1B-light chain 3 (LC3)A/B (cat. no. 4108; Cell Signalling Technology, Inc., Danvers, MA, USA), anti-RIP1 (cat. no. sab3500420; Sigma-Aldrich; Merck KGaA, Darmstadt, Germany), anti-RIP3 (cat. no. prs2283; Sigma-Aldrich; Merck KGaA) and anti-GAPDH (cat. no. G9545; Sigma-Aldrich; Merck KGaA). The secondary antibody used was goat anti-rabbit IgG-phycoerythrin (cat. no. sc-3739; Santa Cruz Biotechnology, Inc., Dallas, TX, USA). A BD FACSAria $^{\mathrm{TM}}$ II flow cytometer (BD Biosciences, Franklin Lakes, NJ, USA) was used for flow cytometry.

Cell culture and grouping. The NRK-52E rat proximal tubular epithelial cell line (70-80\% confluency; ATCC) was cultured in Dulbecco's modified Eagle's medium (Gibco; Thermo Fisher Scientific, Inc.) supplemented with $10 \%$ fetal bovine serum with high glucose. Cells were seeded into 6-well cell culture plates at a density of $5 \times 10^{4} / 1$ in serum-free media for $24 \mathrm{~h}$ to synchronize cell growth. Following this, NRK-52E cells were treated with or without TNF- $\alpha$, zVAD-fmk, antimycin A, and Nec-1 based on the following principles. Cells were divided into the following groups: Ctrl (Control), exposed to nothing; $\mathrm{T}$, exposed to $10 \mathrm{ng} / \mathrm{ml} \mathrm{TNF}-\alpha$ only; TA, exposed to $10 \mathrm{ng} / \mathrm{ml}$ TNF- $\alpha+10 \mu \mathrm{mol} / 1$ antimycin A; TAZ, exposed to $10 \mathrm{ng} / \mathrm{ml}$ $\mathrm{TNF}-\alpha+50 \mu \mathrm{mol} / 1 \mathrm{zVAD}-\mathrm{fmk}+10 \mu \mathrm{mol} / 1$ antimycin A.

Following modelling, each group was divided into two subgroups: +N/A and $+100 \mu \mathrm{mol} / 1 \mathrm{Nec}-1$.

Cell morphological assessment. Cell morphology was observed using an inverted phase contrast microscope. NRK52-E cells possess characteristics of both proximal and distal tubular epithelial cells, and the cells exhibited a single-layer, cobblestone-like arrangement.

Cell viability. Cell viability was evaluated using the Cell Counting kit-8 (CCK-8) (Dojindo Molecular Technologies, Inc., Kumamoto, Japan). Cells (4 wells of each group/subgroup following modelling) were used, and the supernatant was discarded. A total of $100 \mu 110 \%$ CCK- 8 was added to the wells.
After $2 \mathrm{~h}$ of incubation at $37^{\circ} \mathrm{C}$ and $5 \% \mathrm{CO}_{2}$, the cells were assessed using a microplate reader at a wavelength of $450 \mathrm{~nm}$ to assess cell viability using the following calculation: Cell viability $(\%)=[($ model group-blank $) /(\mathrm{Ctl}$ group-blank $)] 100 \%$.

Cell death analysis and necroptosis blocking detection. Following modelling, all media were discarded and the cells were washed with PBS for 3 min, twice. Subsequently, 4\% paraformaldehyde stationary liquid was added (30 $\mathrm{min})$. The cells were washed with PBS (3 min, three times) and $0.5 \mathrm{ml}$ Hoechst 33258 dye $(5 \mathrm{~min})$ was added. Following staining, the cells were washed with three times with PBS for 3 min and mounted with Fluoromount-G mounting medium. Hoechst-stained cells were observed and imaged using confocal laser scanning microscopy. Apoptotic cells were quantified, and the apoptotic index (percentage of apoptotic cells) was calculated (randomly, four high magnification fields were observed; at least 1,000 cells were counted for each data point; repeated in triplicate). The apoptotic index was calculated as: Apoptotic index $=$ (apoptotic cells/counted cells) $\times 100 \%$.

For Annexin V/propidium iodide (PI) double staining, a kit was used according to the manufacturer's instructions (cat. no. KGA108; Nanjing KeyGen Biotech Co., Ltd., Nanjing, China). Following modelling, the cells were centrifuged at a speed of $110 \mathrm{xg}$ at $4^{\circ} \mathrm{C}$ for $3 \mathrm{~min}$ and collected following exposure to $0.25 \%$ trypsin solution (EDTA-free). The medium was discarded, and cells were washed twice with PBS for $3 \mathrm{~min}$. Cells were subsequently resuspended in $400 \mu \mathrm{l} 1 \mathrm{X}$ Binding Buffer. Subsequently, $5 \mu \mathrm{l}$ Annexin V-fluorescein isothiocyanate was added. The solution was mixed and incubated in the dark for $15 \mathrm{~min}\left(2-8^{\circ} \mathrm{C}\right)$. Following this, $5 \mu \mathrm{l}$ propidium iodide (PI) was added. The solution was mixed and incubated in the dark for $5 \min \left(2-8^{\circ} \mathrm{C}\right)$. The cells were assessed within $1 \mathrm{~h}$ using a flow cytometer.

Western blotting. Cells treated under different experimental conditions were lysed with radio-immunoprecipitation assay lysis buffer (BioVision, Inc., Milpitas, CA, USA) The samples were centrifuged $\left(110 \times \mathrm{g}, 4^{\circ} \mathrm{C}, 4 \mathrm{~min}\right)$ and the supernatants were collected as total cell extracts. The protein concentration was determined using the Bicinchoninic Acid assay kit (cat. no. P0010; Beyotime Institute of Biotechnology). Protein (40 $\mu \mathrm{g}$ ) was separated by $10 \%$ SDS-PAGE and transferred onto a polyvinylidene difluoride membrane (Immobilon-P; EMD Millipore, Billerica, MA, USA) by electroblotting. After blocking with non-fat milk for $2 \mathrm{~h}$ at $4^{\circ} \mathrm{C}$, the membranes were incubated overnight at $4^{\circ} \mathrm{C}$ with primary rabbit monoclonal antibodies against RIP1, RIP3 and LC3-B (1:1,000 dilution) and with an anti-GAPDH antibody (1:2,000 dilution) as loading control. Following washing the membranes, the secondary antibody was added (1:500 dilution), and the membranes were incubated for $1 \mathrm{~h}$ at room temperature. Protein bands were visualized using Enhanced Chemiluminescence Plus Western Blotting Detection reagents (cat. no. P0018; Beyotime Institute of Biotechnology) and then exposed to X-ray film (Kodak, Rochester, NY, USA). The bands of the resulting autoradiography were densitometrically quantified using Bandscan software (ImageJ, version 1.48; National Institutes of Health, Bethesda, MD, USA). Protein expression was quantified as the ratio of the specific band to GAPDH. 


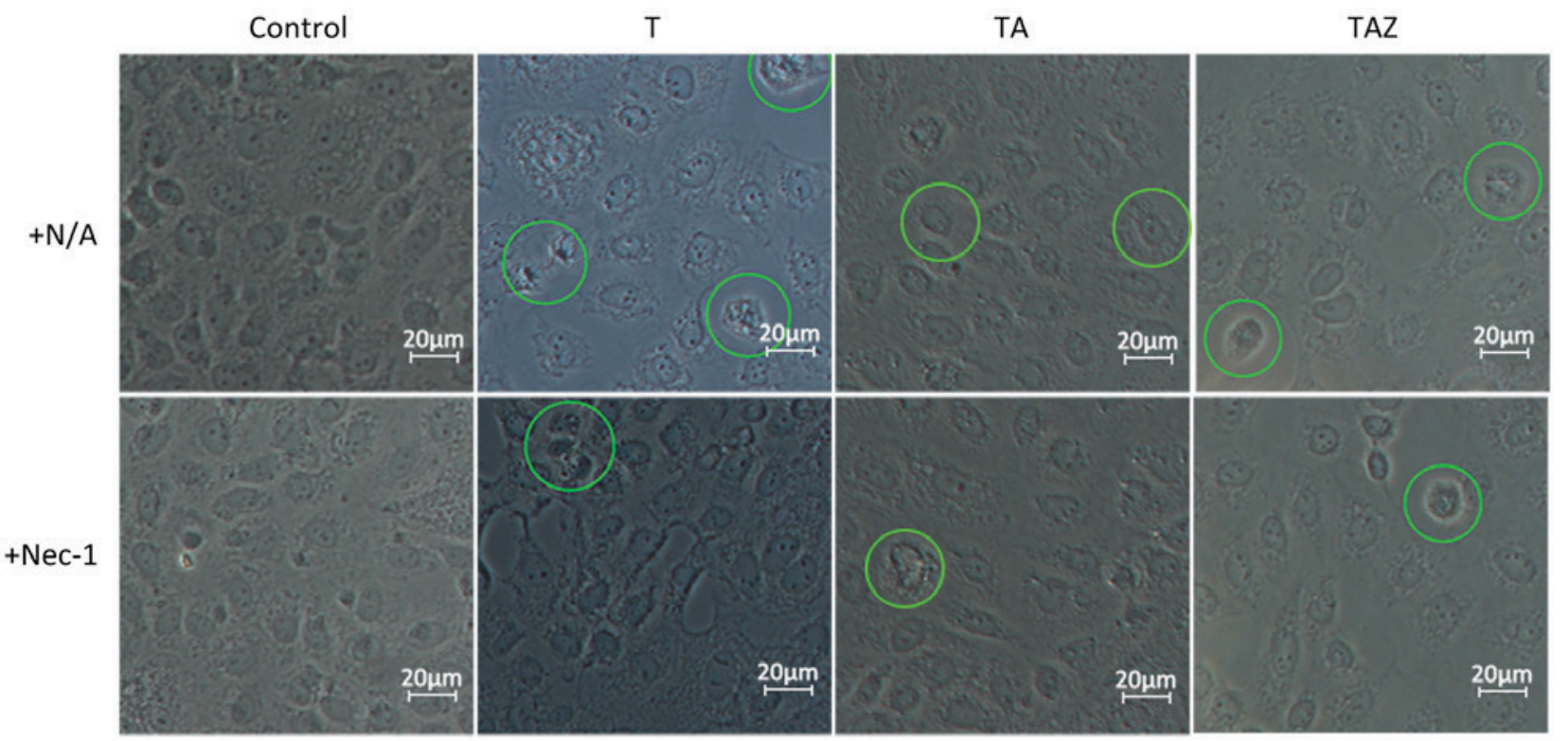

Figure 1. Inverted phase contrast microscope observation. Cells in the $\mathrm{T}$ and TA groups demonstrated apoptotic or necrotic characteristics, whereas most of the cells in the TAZ group exhibited necrotic/necroptotic characteristics. These cells were converted to a more normal morphological status when exposed to Nec-1. T group, exposed to $10 \mathrm{ng} / \mathrm{ml} \mathrm{TNF}-\alpha$ only; TA group, exposed to $10 \mathrm{ng} / \mathrm{ml} \mathrm{TNF}-\alpha+10 \mu \mathrm{mol} / 1$ antimycin A; TAZ group, exposed to $10 \mathrm{ng} / \mathrm{ml} \mathrm{TNF}-\alpha+50 \mu \mathrm{mol} / 1$ zVAD-fmk $+10 \mu \mathrm{mol} / 1$ antimycin A. Nec-1, necrostatin-1; TNF- $\alpha$, tumor necrosis factor- $\alpha$; zVAD-fmk, benzyloxycarbonyl-Val-Ala-Asp-fluoro-methylketone.

Statistical analysis. Each subgroup comprised at least 16 wells of cells, which were randomly assigned to different conditions. Calculations were performed using SPSS software (version 13.0; SPSS Inc., Chicago, IL, USA). Data are expressed as the mean \pm standard deviation. One-way analysis of variance followed by post hoc least significant differences test or Dunnett's t-test was used to compare the differences between groups. $\mathrm{P}<0.05$ was considered to indicate a statistically significant difference.

\section{Results}

Cell necroptosis hypoxic-ischemic injurymodel in rat NRK52-E cells is successfully established by using TNF- $\alpha$, antimycin A and $z V A D-f m k$. Inverted phase contrast microscopy revealed that the Ctl group cells had an irregular or oval morphology with an oval nucleus in the center. The cells were arranged on the bottom of the culture flask, like paving stones, in the absence of injury factors. Certain cells in the T and TA groups exhibited apoptotic characteristics, became smaller or irregular in shape, and exhibited cell fragmentation and cytoplasm condensation. Certain cells demonstrated necrotic characteristics, including swelling and rupturing of the plasma membrane. In the TAZ group, apoptosis was rarely observed. Most of the cells in this group exhibited necrotic/necroptotic characteristics, including cell membrane destruction, cell and organelle swelling, a dissolved nucleolus and reduced refraction. A subgroup of TAZ cells exposed to Nec-1 exhibited an enhanced morphological status, and more cells appeared normal, indicating that Nec-1 provided a protective effect (Fig. 1). In the TAZ group, apoptosis was inhibited by the caspase inhibitor, zVAD-fmk. These results indicated that RIP1 and RIP3 expression increased during key switches of cell death from apoptosis to necroptosis (14). In addition, in the TAZ + Nec-1 group, the expression of these proteins was inhibited by Nec-1 (Fig. 2).

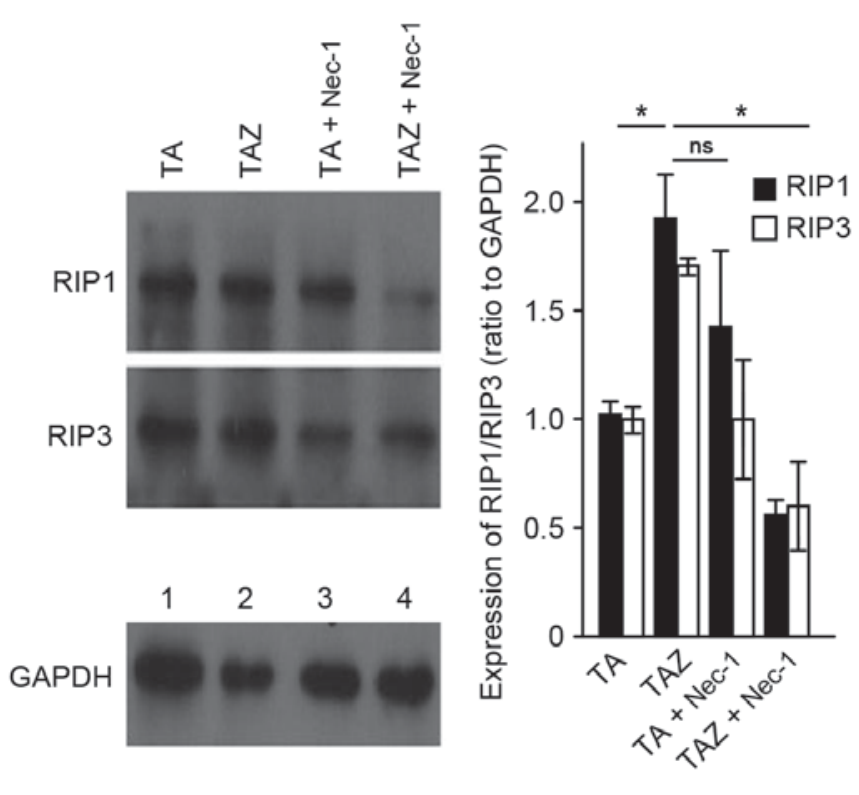

Figure 2. RIP1/RIP3 expression. When apoptosis was inhibited by the caspase inhibitor zVAD-fmk in the TAZ group, the key switches of cell death from apoptosis to necroptosis revealed an increase in the expression of RIP1 and RIP3, which can be inhibited by Nec-1. Data are presented as the mean \pm standard deviation. ${ }^{*} \mathrm{P}<0.001$, with comparisons indicated by lines. TA group, exposed to $10 \mathrm{ng} / \mathrm{ml}$ TNF- $\alpha+10 \mu \mathrm{mol} / 1$ antimycin A; TAZ group, exposed to $10 \mathrm{ng} / \mathrm{ml} \mathrm{TNF}-\alpha+50 \mu \mathrm{mol} / 1 \mathrm{zVAD}-\mathrm{fmk}+10 \mu \mathrm{mol} / 1$ antimycin A RIP, receptor-interacting protein kinase; TNF- $\alpha$, tumor necrosis factor- $\alpha$; zVAD-fmk, benzyloxycarbonyl-Val-Ala-Asp-fluoro-methylketone; ns, not significant.

Nec-1 exhibited a protective effect in the rat NRK52-E cell injury model. Compared with the Ctl group, all of the modelling groups exhibited reduced cell viability. The TAZ group demonstrated the lowest cell viability among all of the modelling groups. With all subgroups exposed to Nec-1, only the 


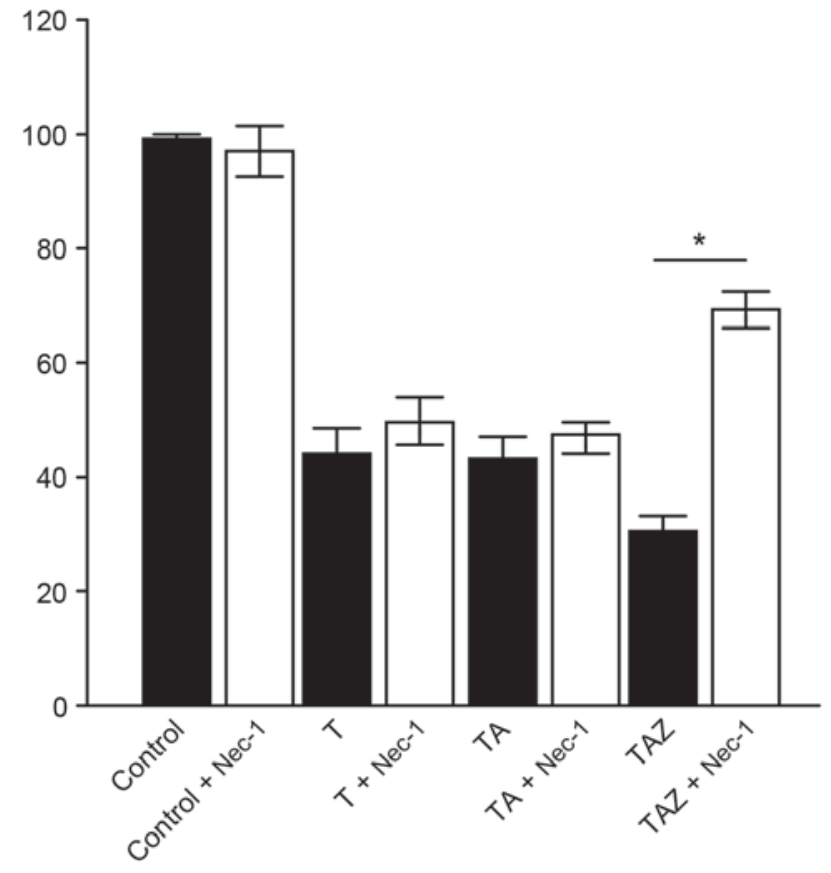

Figure 3. Cell viability of NRK52-E. The cell viabilities of all treated groups were reduced compared with the control group, particularly the TAZ group. Exposure to Nec-1 significantly promoted cell viability in the TAZ group, which was not significantly different from the control group. Data are expressed as the mean \pm standard deviation. ${ }^{*} \mathrm{P}<0.05$ with comparison indicated by the line. T group, exposed to $10 \mathrm{ng} / \mathrm{ml}$ TNF- $\alpha$ only; TA group, exposed to $10 \mathrm{ng} / \mathrm{ml} \mathrm{TNF}-\alpha+10 \mu \mathrm{mol} / 1$ antimycin A; TAZ group, exposed to $10 \mathrm{ng} / \mathrm{ml} \mathrm{TNF-} \alpha+50 \mu \mathrm{mol} / 1 \mathrm{zVAD}-\mathrm{fmk}+10 \mu \mathrm{mol} / 1$ antimycin A. Nec-1, necrostatin-1; TNF- $\alpha$, tumor necrosis factor- $\alpha$; zVAD-fmk, benzyloxycarbonyl-Val-Ala-Asp-fluoro-methylketone.

TAZ + Nec-1 group demonstrated significant differences of increased cell viability compared with cells not treated with Nec-1 $(\mathrm{P}<0.05$; Fig. 3). No significant differences in cell viability were noted in the $\mathrm{Ctl}$ group with or without exposure to Nec-1 (P>0.05; Fig. 3).

Flow control effect of cell death is potentially the mechanism underlying the protective effect of Nec-1. All three mechanisms of cell death (necrosis, apoptosis and necroptosis) occur when cells are exposed to injurious factors. More cells undergo apoptosis when exposed to antimycin A, whereas zVAD-fmk inhibits apoptosis and forces the cells to die in an apoptosis-independent manner. When Nec-1 interferes with the necroptosis signalling pathway, it appears to regulate flow control behaviour. Nec-1 inhibited the necroptosis signalling pathway and induced cells to undergo necrosis and apoptosis. Hoechst staining indicated that more cells committed to the apoptosis signalling pathways in the TA group. In the presence of Nec-1, more cells died via apoptosis compared with the $+N / A$ subgroup. Among all of the modelling groups outside the control group, the TAZ group exhibited the lowest apoptosis rate (Fig. 4). In addition, Annexin V/PI staining demonstrated that the apoptosis rate increased in addition to other subjoining injury factors. However, the rate decreased when zVAD-fmk (a caspase inhibitor) was added. All subgroups with the addition of Nec-1 exhibited an increased apoptosis rate, and the TA + Nec-1 group exhibited the highest apoptosis rate (25.50 $\pm 6.15 \%$; Fig. 5).
Nec-1 combined with zVAD-fmk downregulates autophagy marker LC3-B. In vitro western blotting revealed that Nec-1 addition had no effect on LC3-B protein expression levels in the control and $\mathrm{T}$ groups ( $\mathrm{P}>0.05$; Fig. 6). LC3-B expression levels were higher in the TA and TAZ groups compared with control $(\mathrm{P}<0.05$; Fig. 6$)$, and when Nec-1 was added, this effect was reversed, with LC3-B expression being significantly downregulated in the $\mathrm{TZ}(\mathrm{P}<0.05)$ and $\mathrm{TAZ}(\mathrm{P}<0.01)$ groups $($ Fig. 6).

\section{Discussion}

AKI is a type of functional and structural disorder or sign of renal damage. AKI is mainly caused by a decrease in renal or intra-renal perfusion and in certain cases is fatal, with a mortality rate of $>60 \%(15,16)$. Ischemia-reperfusion injury is a major cause of AKI, and this type of injury is particularly harmful to RTECs. The key to controlling the prognosis of AKI involves reducing the death rate of RTECs (17). RTECs may die via various mechanisms: Apoptosis, autophagy, necrosis or necroptosis. Apoptosis induces less damage to the surrounding tissue because the cell contents do not leak out during the process (4). However, the leakage of inflammatory substances may lead to serious injury to the surrounding cells when RTECs die via the necrosis pathway (18).

Our previous study revealed that TNF- $\alpha$ induces apoptosis and necroptosis (11). However, as demonstrated in the present study, necroptosis did not occur when TNF- $\alpha$ was combined with zVAD-fmk. The current study identified that antimycin A plus TNF- $\alpha$ combined with zVAD-fmk generates a nearly apoptosis-free model with a cell apoptosis rate of $7.03 \pm 0.40 \%$ vs. the control group $(4.07 \pm 0.20 \%)$. In addition, Annexin V/PI staining strengthened this conclusion, demonstrating a cell apoptosis rate of $7.49 \pm 1.65$ vs. $4.77 \pm 1.96 \%$ in the control group. Using this model, further research is required in order to fully elucidate the effects of Nec-1 in AKI.

In current study, cell morphology and CCK-8 cell viability results revealed significant differences in the TAZ group treated with and without Nec-1, and cell viability increased from $30.77 \pm 1.66$ to $69.36 \pm 1.69 \%$. Furthermore, Nec-1 exhibited minimal toxic effects in response to NRK52-E. In the control group, Nec-1 exposure resulted in a cell viability rate of $95.56 \pm 6.05 \%$. Therefore, Nec-1 clearly provides a protective effect to the TAZ group. However, no differences were observed between the T and TA groups, and the mechanism may be explained as follows.

When a cell confronts overwhelming injury factors, including a high concentration of TNF, antimycin A, and severe hypoxic-ischemic injury similar to that simulated in in vitro models, the cell may die via four mechanisms: Necrosis, apoptosis, autophagic death or necroptosis. Without regulation, all of the above pathways exist, but only a small number of cells undergo necroptosis. Therefore, Nec-1 cannot provide a protective effect to the $\mathrm{T}$ and TA groups. In the presence of zVAD-fmk, which inhibits pan-caspase pathways, the apoptosis rate decreased and cell viability did not increase. These results indicated that many cells undergo other cell death pathways, including necrosis and necroptosis. Furthermore, the addition of Nec-1 protected a large number of cells from dying and directly led to an $\sim 40 \%$ increase in cell viability. Furthermore, certain cells sustained significant injury from 


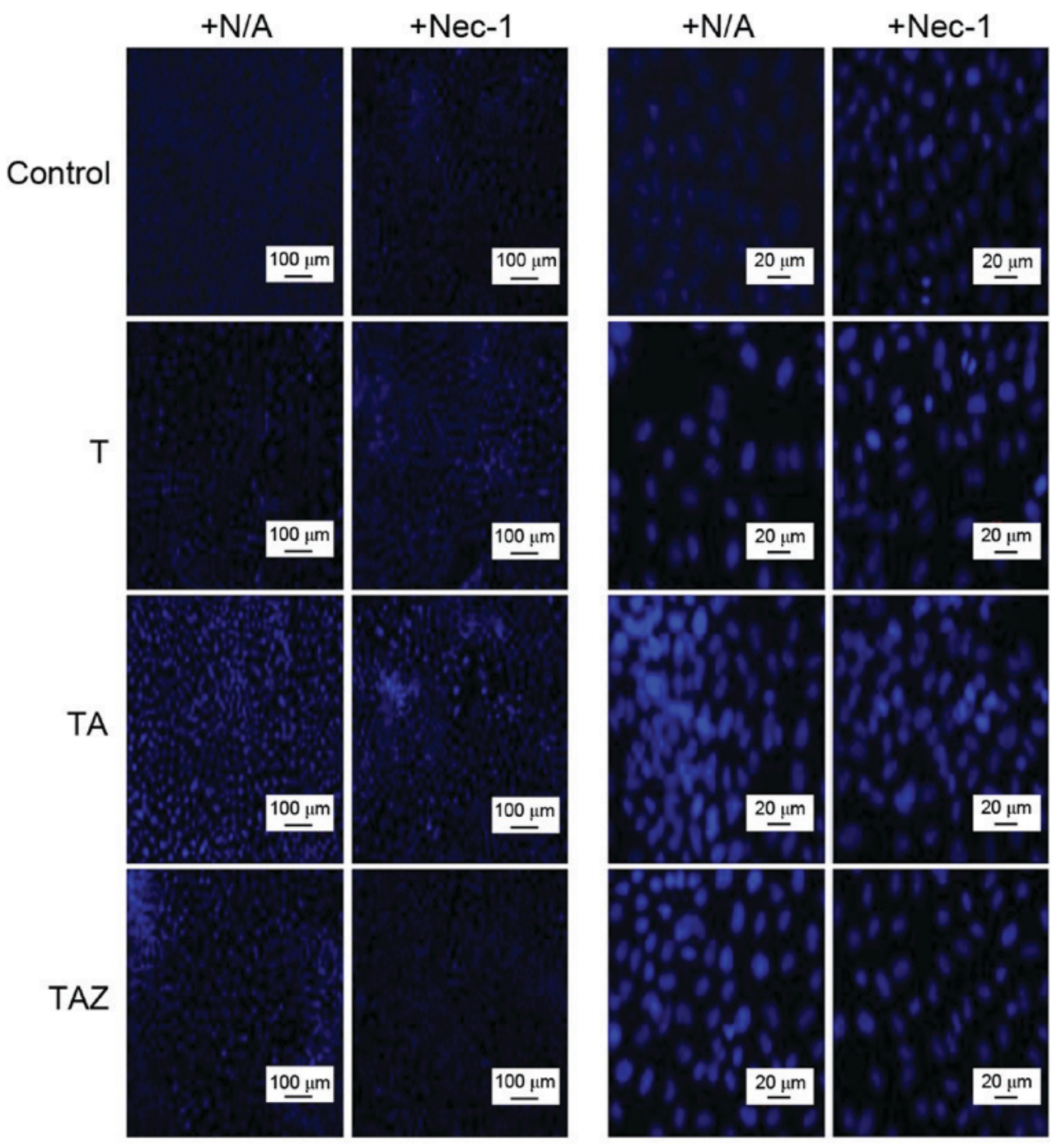

Figure 4. Hoechst staining imaged under confocal laser scanning microscopy. The highest rate of apoptosis occurred in the TA group, and the lowest rate of apoptosis was noted in the TAZ group with or without Nec-1 (with the exception of the control group) based on the Hoechst staining test. T group, exposed to $10 \mathrm{ng} / \mathrm{ml} \mathrm{TNF-} \alpha$ only; TA group, exposed to $10 \mathrm{ng} / \mathrm{ml} \mathrm{TNF-} \alpha+10 \mu \mathrm{mol} / 1$ antimycin A; TAZ group, exposed to $10 \mathrm{ng} / \mathrm{ml} \mathrm{TNF}-\alpha+50 \mu \mathrm{mol} / 1$ zVAD-fmk + $10 \mu \mathrm{mol} / 1$ antimycin A. Nec-1, necrostatin-1; TNF- $\alpha$, tumor necrosis factor- $\alpha$; zVAD-fmk, benzyloxycarbonyl-Val-Ala-Asp-fluoro-methylketone.
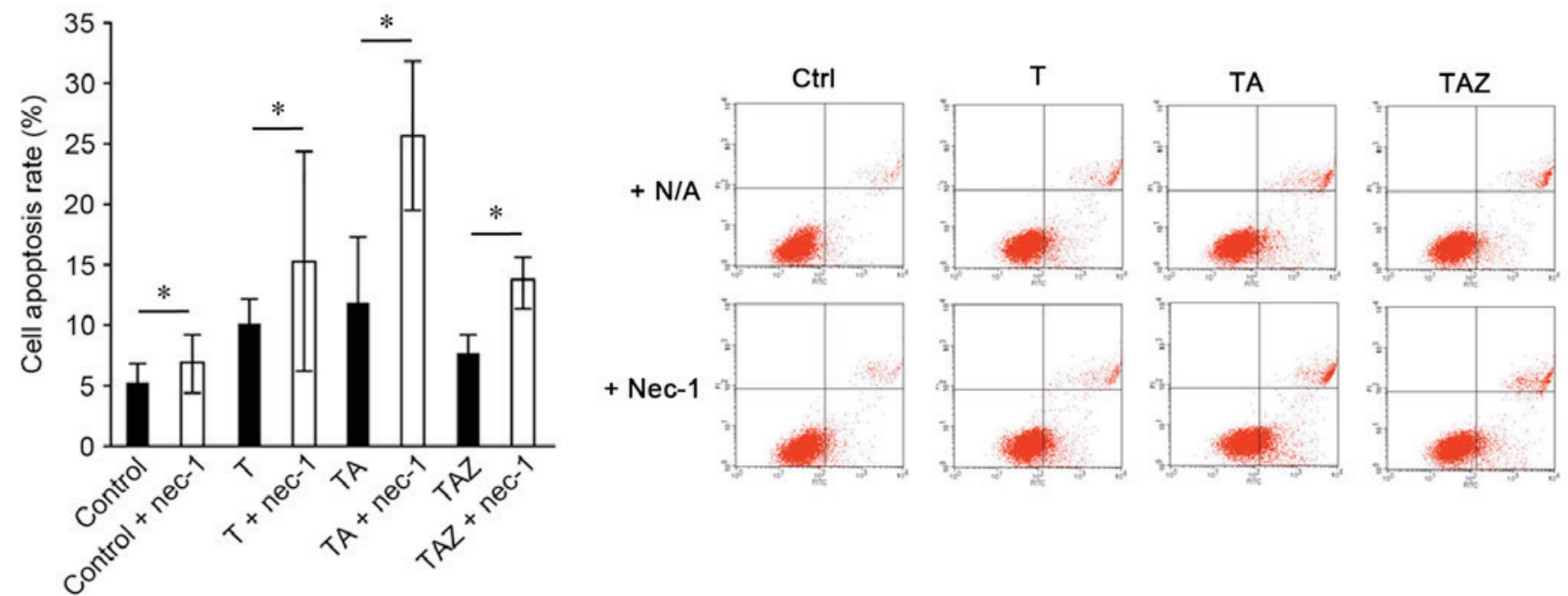

Figure 5. Cell apoptosis rate (\%) based on Annexin V/PI staining and flow cytometry. Quantification and representative plots of Annexin V/PI staining in NRK-52E cells. * $\mathrm{P}<0.05$, with comparisons indicated by lines. PI, propidium iodide; Nec-1, necrostatin-1. T group, exposed to 10 ng/ml TNF- $\alpha$ only; TA group, exposed to $10 \mathrm{ng} / \mathrm{ml}$ TNF- $\alpha+10 \mu \mathrm{mol} / 1$ antimycin A; TAZ group, exposed to $10 \mathrm{ng} / \mathrm{ml} \mathrm{TNF}-\alpha+50 \mu \mathrm{mol} / 1 \mathrm{zVAD}-\mathrm{fmk}+10 \mu \mathrm{mol} / \mathrm{l}$ antimycin A. Nec-1, necrostatin-1; TNF- $\alpha$, tumor necrosis factor- $\alpha$; zVAD-fmk, benzyloxycarbonyl-Val-Ala-Asp-fluoro-methylketone. 

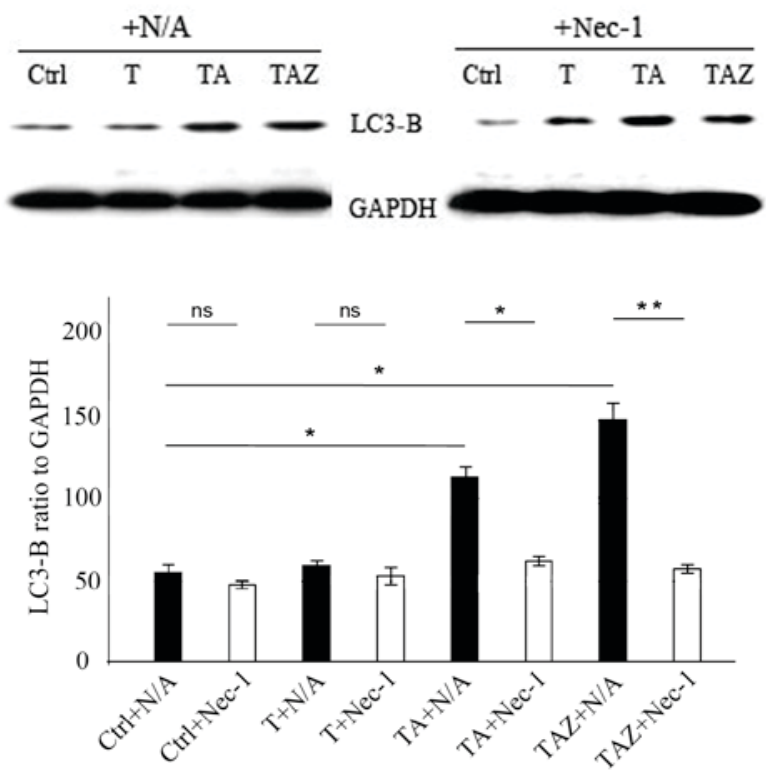

Figure 6. LC3-B expression in NRK-52E cells. Representative western blot images and quantification of LC3-B protein expression levels relative to GAPDH loading control. ${ }^{*} \mathrm{P}<0.05$ and ${ }^{* *} \mathrm{P}<0.01$, with comparisons indicated by lines. T group, exposed to $10 \mathrm{ng} / \mathrm{ml} \mathrm{TNF}-\alpha$ only; TA group, exposed to $10 \mathrm{ng} / \mathrm{ml}$ TNF- $\alpha+10 \mu \mathrm{mol} / 1$ antimycin A; TAZ group, exposed to $10 \mathrm{ng} / \mathrm{ml} \mathrm{TNF}-\alpha+50 \mu \mathrm{mol} / 1 \mathrm{zVAD}-\mathrm{fmk}+10 \mu \mathrm{mol} / 1$ antimycin A. Nec-1, necrostatin-1; TNF- $\alpha$, tumor necrosis factor- $\alpha$; zVAD-fmk, benzyloxycarbonyl-Val-Ala-Asp-fluoro-methylketone; microtubule-associated protein 1A/1B-light chain 3; ns, not significant.

damaging factors to the extent that could not avoid dying due to Nec-1 inhibition of the necroptosis pathway. All subgroups exposed to Nec-1 exhibited an observable increase in apoptosis, which was confirmed by Hoechst staining and Annexin V/PI staining. The study attempted to control this and inhibit the apoptosis and necroptosis pathways. Subsequently, certain cells could not be saved, but the largest alternative pathway was blocked which increased cell viability by $38.59 \%$, thereby reducing cell death by $44.26 \%$. This is a notable finding.

LC3-B is associated with the formation of autophagosomes, and an increase in LC3-B is a main biochemical parameter of autophagy (19). In the current research, the expression of LC3-B in the TAZ group increased, indicating that autophagic death was present and served an important role in cell death (20-22). However, the expression of LC3-B decreased and was almost close to normal levels upon exposure to Nec-1 in the TAZ group, suggesting that Nec-1 combined with zVAD-fmk reduced autophagy and provided a protective effect to hypoxic-ischemic injury in RTECs.

In conclusion, the present study established a novel method to generate a necroptosis cell line model, and demonstrated that Nec-1 has a protective effect on RTECs via a flow-control-like effect.

\section{Acknowledgements}

This study was supported by the National Natural Science Foundation of China (grant no. 81570609) and the Natural Science Foundation of Guangdong Province (grant no. 2014A030313545) and the National Clinical Key Specialty Construction Preparatory Projects.

\section{References}

1. Ricci $Z$ and Ronco C: New insights in acute kidney failure in the critically ill. Swiss Med Wkly 142: w13662, 2012.

2. Bagshaw SM: The long-term outcome after acute renal failure. Curr Opin Crit Care 12: 561-566, 2006.

3. Heyman SN, Evans RG, Rosen S and Rosenberger C: Cellular adaptive changes in AKI: Mitigating renal hypoxic injury. Nephrol Dial Transplant 27: 1721-1728, 2012.

4. Tharaux PL and Huber TB: How many ways can a podocyte die? Semin Nephrol 32: 394-404, 2012.

5. Muppidi J, Porter M and Siegel RM: Measurement of apoptosis and other forms of cell death. Curr Protoc Immunol Chapter 3: Unit 3.17, 2004.

6. Fulda S: The mechanism of necroptosis in normal and cancer cells. Cancer Biol Ther 14: 999-1004, 2013.

7. Webster KA: Mitochondrial membrane permeabilization and cell death during myocardial infarction: Roles of calcium and reactive oxygen species. Future Cardiol 8: 863-884, 2012.

8. Linkermann A, Hackl MJ, Kunzendorf U, Walczak H, Krautwald S and Jevnikar AM: Necroptosis in immunity and ischemia-reperfusion injury. Am J Transplant 13: 2797-2804, 2013.

9. Moriwaki K and Chan FK: RIP3: A molecular switch for necrosis and inflammation. Genes Dev 27: 1640-1649, 2013.

10. Christofferson DE and Yuan J: Necroptosis as an alternative form of programmed cell death. Curr Opin Cell Biol 22: 263-268, 2010.

11. Zhang L, Jiang F, Chen Y, Luo J, Liu S, Zhang B, Ye Z, Wang W, Liang $X$ and Shi W: Necrostatin-1 attenuates ischemia injury induced cell death in Rat tubular cell line NRK-52E through decreased Drp1 expression. Int J Mol Sci 14: 24742-24754, 2013.

12. Vandenabeele P, Galluzzi L, Vanden Berghe T and Kroemer G: Molecular mechanisms of necroptosis: An ordered cellular explosion. Nat Rev Mol Cell Biol. 11: 700-714, 2010.

13. Plaisance I, Duthe F, Sarrouilhe D and Hervé JC: The metabolic inhibitor antimycin A can disrupt cell-to-cell communication by an ATP- and $\mathrm{Ca}(2+)$-independent mechanism. Pflugers Arch 447: 181-194, 2003.

14. Zhang DW, Shao J, Lin J, Zhang N, Lu BJ, Lin SC, Dong MQ and Han J: RIP3, an energy metabolism regulator that switches TNF-induced cell death from apoptosis to necrosis. Science 325 : 332-336, 2009.

15. Coca SG, Yusuf B, Shlipak MG, Garg AX and Parikh CR: Long-term risk of mortality and other adverse outcomes after acute kidney injury: A systematic review and meta-analysis. Am J Kidney Dis 53: 961-973, 2009.

16. Li PK, Burdmann EA and Mehta RL; World Kidney Day Steering Committee 2013: Acute kidney injury: Global health alert. Transplantation 95: 653-657, 2013.

17. Yang JR, Yao FH, Zhang JG, Ji ZY, Li K, Zhan J, Tong YN, Lin LR and He YN: Ischemia-reperfusion induces renal tubule pyroptosis via the CHOP-Caspase-11 pathway. Am J Physiol Renal Physiol 306: F75-F84, 2014.

18. González-Guerrero C, Ocaña-Salceda C, Berzal S, Carrasco S, Fernández-Fernández B, Cannata-Ortiz P, Egido J, Ortiz A and Ramos AM: Calcineurin inhibitors recruit protein kinases JAK2 and JNK, TLR signaling and the UPR to activate NF- $\mathrm{BB}$-mediated inflammatory responses in kidney tubular cells. Toxicol Appl Pharmacol 272: 825-841, 2013.

19. Smirnova E, Griparic L, Shurland DL and van der Bliek AM: Dynamin-related protein Drp1 is required for mitochondrial division in mammalian cells. Mol Biol Cell 12: 2245-2256, 2001.

20. Tanaka A and Youle RJ: A chemical inhibitor of DRP1 uncouples mitochondrial fission and apoptosis. Mol Cell 29: 409-410, 2008.

21. Liu J, Chen Z, Zhang Y, Zhang M, Zhu X, Fan Y, Shi S, Zen K and Liu Z: Rhein protects pancreatic $\beta$-cells from dynamin-related protein-1-mediated mitochondrial fission and cell apoptosis under hyperglycemia. Diabetes 62: 3927-3935, 2013.

22. Frank S, Gaume B, Bergmann-Leitner ES, Leitner WW, Robert EG, Catez F, Smith CL and Youle RJ: The role of dynamin-related protein 1, a mediator of mitochondrial fission, in apoptosis. Dev Cell 1: 515-525, 2001. 